\title{
ICNOFÓSSEIS EM AFLORAMENTOS DO RIO GRANDE DO SUL: NOTA PRELIMINAR
}

Tânia L. Dutra (NESE/UNISINOS)

Renata G. Netto (NESE/UNISINOS)

Carlos H. Nowatzki (NESE/UNISINOS)

Cláudio E. Zarif Figueiredo (CNPq - bolsista)

Este trabalho apresenta os primeiros resul tados de um levantamento que vem sendo realizado pelo grupo de pes quisadores do NESE/UNISINOS, objetivando a atualização dos dados referentes aos afloramentos fossiliferos do Estado do Rio Grande do sul.

Nesta tentativa procura-se resgatar os traba lhos pioneiros de Zingano e Cauduro(1959) e Pinto e Closs(1967), que empreenderam tarefa semelhante, trazendo contribuições à luz dos no vos conhecimentos em geologia e das novas descobertas realizadas. De seja-se,com isto, propiciar a estudantes, pesquisadores e comunidade, um conhecimento mais aprupriado e fácil daquelas regiões do nosso Estado que, por seu valor científico, devem merecer atenção e cuidado.

Já a decisão de iniciar esta abordagem pelos los icnofösseis, deveu-se a duas razões principais: constituirem uma área de estudos relativamente recente e, portanto, ausente daque les primeiros enfoques e possuirem elementos que filosófica e metodologicamente, os situam na interface dos conhecimentos da sedimento logia e da paleontologia, atendendo ao que se propoẽm e vem traba lhando o grupo de pesquisadores.

Os icnofósseis possuem ainda, particularmente quando associados às estruturas sedimentares, a vantagem de serem um excelente instrumento para as reconstituições paleoambientais e pa leoecológicas(Seilacher,1967 e Crimes,1970 e Frey e Pemberton,1984) das deposições onde são encontrados.

Na realização do trabalho foram percorridos cerca de $5000 \mathrm{~km}$, concentrados na faixa de ocorrência dos sedimentos gondwânicos e na porção do Escudo Sul-riograndense, referente as rochas de idade Eopaleozóico, sendo identificados 25 locais onde os ic nofósseis estão presentes. Destes, foram selecionados cinco, por reu nirem as assembléias mais representativas, exemplares melhor preser- 
vados e acesso mais fácil.

Para cada um deles, serão fornecidos, em trabalho posterior, os seguintes elementos:

a) local de ocorrência com denominação lo cal, quando houver, e suas coordenadas geográficas;

b) unidades litoestratigráficas presentes

e idade;

c) icnofósseis presentes, com sua ilustração e possível caracterização sistemática;

d) perfil do afloramento, com indicação dos niveis fossilíferos;

e) referências bibliográficas.

As estruturas encontradas nas rochas da Ba cia do Camaquã, dada sua ainda duvidosa associação à atividade de organismos, merecerão estudo mais detalhado, não tendo sido aqui incluidas.

Os seguintes locais foram selecionados pa ra esta primeira abordagem:

1. Afloramento do Cambai Grande (53058'36"W/30017'03"s) que, junto ao de Vila Nova Norte (53256'12"W/30019'36"s), situa-se na Fo lha Vila Nova.

Nestes locais ocorrem sedimentitos que vinham sendo tratados na literatura como pertencentes ao Grupo Itararé (Formação Rio do sul de Schneider et al.,1974). Em traba lho recente, Andreis et al.(1989) baseados na análise das estru turas sedimentares e nos fósseis, como já contando com parte da sedimentação basal da Formação Rio Bonito. A idade é Permiano.

A presença marcante de Arenicolites sp. , preservado como "exichnia", em formas verticalizadas e horizo.talizadas nos sedimentos, caracteriza a ocorrência. Para estes locais, já haviam sido identificados Neonereites sp. Seila cher, 1960 e formas duvidosas relacionadas com Skolithos, por Netto (1987).

2. Afloramento da Cascatinha (52049'50"W/30018'04"S), na Folha de Cachoeira do sul.

Os niveis, pertencentes a Formação Rio Bonito e Palermo, segundo Lavina et al.(1985) parecem demonstrar um episódio transgressivo, com depósitos de leques aluviais e deltaicos, na porção inferior, lagunas e ilhas de bar reira, na porção média e marinho raso, superiormente. Os icnofósseis, distribuidos ao longo do perfil, também mostram esta gradação para fácies cada vez mais profundas, por sua associa ção, na seguinte sequência: assembléias de planicie de maré, fá 
cies Skolithos, fácies Cruziana e, finalmente, assembléias associadas às "sand waves". A idade é Permiano.

Os seguintes icnogêneros foram identifica dos no afloramento: Arenicolites Salter,1857, Thalassinoides, Di plocraterium, Rosselia Dahmer,1937, Skolithos Haldeman,1840, Te $\underline{i}$ chichnus Seilacher, 1955, em trabalho de Netto e Gonzaga(1985) , Cochlichnus e Planolites.

Niveis igualmente interessantes pelo con teúdo fossilifero semelhante, ocorrem ainda, na parte correspondente a Formação Rio Bonito, em Corredores (53020'00"W/30021'35" S), na Folha de Durasnal. Aí, chama a atenção o expressivo tamanho e espessura das bioturbações, preenchidas por areia, nos niveis pelíticos escuros com "clibing",evidenciando condições de deposição deltaica(Lavina et al.,1985) .

3. Afloramento Coxilha de Santana (55029'35"W/30053'41"S) na Folha Palomas. No Cerro Palomas, na Br 253 e na Sanga da Divisa(55024' $\left.00 \mathrm{~W} / 30059^{\prime} 40^{\mathrm{S}} \mathrm{S}\right)$, temos ocorrências semelhantes.

As estruturas sedimentares indicam uma deposição em ambiente eólico e foram associadas por Lavina e Azevedo (1983) e Andreis (1989), a Formação Sanga do Cabral. Os icnofós seis estão registrados nas areias e em pelitos de pequena espessura, indicando a presença de ägua, na região interdunas. A forma presente, Anchorichnus coronus, ora registrada de forma verti calizada, ora horizontal e, com preenchimento meniscado dos tubos, possui grande valor como indicador paleoambiental, por se rem das poucas icnoespécies que identificam deposições de cará ter continental (Frey et al.,1984 in Netto,1989).

Uma idade Triássica é atribuída aos sedimentos.

4. Afloramento Cerro das Caveiras (54048'18"W/30054'43"S), na Folha de Dom Pedrito.

Junto com o afloramento ao longo do km 263 da $\mathrm{Br} 293$, as exposições do Cerro das Caveiras constituem as mais significativas e importantes, em termos da assembléia de icnofósseis presentes. Distribuem-se ao longo de todo o perfil, onde aparecem as intercalações de areias e pelitos e freqüente mente estão associados as marcas de ondulações. Esta ocorrência é constante, no Estado, para o Membro Serrinha da Formação Rio do Rasto(Nowatzki et al.,1983 e Netto,1988). Idade: Permiano Superior.

As formas presentes foram estudadas por Net to(op.cit.) e são: Cochlichnus Hitchcock, 1859, Helminthopsis tenuis Ksiazkiewicz, 1970, Isopodichnus problematicus Schindewolf, 
1928, ?Oldhamia flabellata Aceñolaza e Duran, 1982, Planolites beverleyensis (Billings,1862) , Planolites montanus Richter1937 e Unarites sp. MacSotay,1967, além de outros exemplares de identificação incerta. No conjunto, estes elementos caracterizam a fácies Cruziana de Frey e Pemberton(op.cit.), indicando ambientes onde a deposição ocorre nos momentos de baixa a moderada energia, demonstrado pelo domínio das formas horizontalizadas.

5. Afloramento de Tiarajú (54914'42"W/30011'47"S), na Folha de Tiarajú.

Assemelha-se em importância ao afloramento

anterior.

A unidade presente é o mesmo Membro Serrinhạ da Formação Rio do Rastro(Schneider et al.,1974) porém, aqui, aparecem niveis estratigraficamente colocados, acima e abaixo daqueles expostos no Cerro das Caveiras. Isto de deve a maior extensão e número de afloramentos que, além do já citado se distribuem em torno da cidade de são Gabriel.

o conjunto das bioturbações é praticamente o mesmo, aparecendo aqui duas formas novas, Teichichnus rectus e Thalassinoides suevicus e desaparecendo ?Oldhamia e Cochli chnus. Esta particularidade levou Netto(1988) a reunir estes e xemplares em uma assembléia distinta daquela de Tiarajú, a qual chamou de Icnocenose A, indicadora de deposições mais rápidas , em ambiente de moderada energia, em uma planície de maré.

\section{BIBLIOGRAF IA}

ANDREIS,R.R. 1989. Integração litoestratigráfica das sequências triássicas Sul-riograndenses e do Norte-Uruguaio. Relatório FAPERGS- Proc.1379/88. Inédito.

ANDREIS,R.R.,ROLON,A. e DUTRA,T.L. 1989. O afloramento de Cam baí Grande, uma nova interpretação. In: INTERNATIONAL CON GRESS OF CARBONIFEROUS- PERMIAN STRATIGRAPHY AND GEOLOGY, 11 Buenos Aires, 1989. Anais... Buenos Aires.

CRIMES,T.P.1973. Trace Fossils. Sedimentology,20(1):119-131. FREY,R.W. e PEMBERTON,S.G. 1984. Trace fossils facies models. In WALKER,R.G. ed. Facies Models. Canadá, Geoscience. Reprint Series 1 .

LAVINA,E.L. e AZEVEDO,S.A. 1983. Geologia da Folha de Posto / Queimado, RS. Convenio URGS-FINEP 33.82.0324.00. Instituto de Geosciencias, Pôrto Alegre, Mapa 2 (Relatório Interno). LAVINA,E.L. ,NOWATZKI,C.H. ,SANTOS,M.A. e LEÃO,H.Z. 1985. Ambientes de sedimentação do Super-Grupo Tubarão na região de Ca eira do Sul, RS. Acta Geologica Leopoldensia, 21:5-76 
NETTO,R.G. 1987. Sobre a ocorrência de Neonereites Seilacher, 1960 no Permiano do Rio Grande do Sul. In: CONGRESSO BRASILEIRO DE PALEONTOLOGIA, 10, Rio de Janeiro, 1987. Anais... Rio de Janeiro, SBP, p. 285-287.

NETTO,R.G. 1988. Paleoicnologia dos sedimentitos basais da Forma ção Rio do Rasto, no Rio Grande do Sul. Tese (Mestrado). Curso de Pós-Građuação em Geosciências, UFRGS. Pôrto Alegre.

NETTO,R.G. 1989. Paleoicnologia das sequências eólicas sotopostas à Formação Botucatú no Rio Grande do Sul. Acta Geologica Leopoldensia, 28.31-44.

NOWATZKI,C.H., SANTOS,B.R.,SANTOS,M.A. e GONZAGA,T.D. 1983. Atlas de estruturas sedimentares Pré-Gondwânicas e Gondwânicas do Estado do Rio Grande do Sul, Brasil. Parte II. Estruturas Sedimen tares Químicas e Orgânicas. Acta Geologica Leopoldensia, 15: 5 32 .

PINTO,I.D. e CLOSS,D. 1967. Indice remissivo dos fósseis do Rio Grande do Sul. Iheringia, 1:3-76.

SCHNEIDER, R. L. ,MUHLMANN, H. , TOMMASI, E. ,MEDEIROS, R. A. , DAEMON, R. F. e NOGUEIRA,A.A. 1974. Revisão estratigráfica da Bacia do Paraná . In: CONGRESSO BRASILEIRO DE GEOLOGIA, 28, Pôrto Alegre,1974. nais..., , 1., SBG, p. 41-65.

SEILACHER,A., 1967. Bathymetry of Trace Fossils. Marine Geology, 5 : 413-428.

ZINGANO,A.G. e CAUDURO,A.C. 1959. Afloramentos fossilíferos do Rio Grande do Sul. Boletim ICN, 8:1-48. 
